\title{
Application of multiscale approaches to the investigation of sealing surface deformation for the improvement of leak tightness in pressure relief valves
}

\author{
Ali A. Anwar, Yevgen Gorash and William Dempster
}

\begin{abstract}
This chapter is part of a research program to investigate and model the leak tightness of a Pressure Relief Valve (PRV). Presented here is: a literature review; high temperature numerical study involving the deformation of contact faces for a metal-to-metal seal accounting for micro and macro effects; and also microscopic measurements of surface finishes and how they are modelled over a micro to nanometer scale. Currently, no review of literature exists which attempts to understand the leakage phenomenon of metal-to-metal seal contact PRV for static closed positions as they reach the set pressure point. This work attempts to do just that by drawing on inspiration from other research areas such as metal-to-metal contact and gasket seals. The key topics of interest surrounding the leakage of fluid through a gap are: fluid flow assumptions, surface characteristics and its deformation, and experimental techniques used to quantify leakage. For the numerical study, the valve geometry is simplified to an axisymmetric problem, which comprises a simple geometry consisting of only three components: a cylindrical nozzle, which is in contact with a disc (representing the valve seat on top), which is preloaded by a compressed linear spring. The nozzle-disk pair is made of the austenitic stainless steel AISI type $316 \mathrm{~N}(\mathrm{~L})$ steel. In a previous study, the macro-micro interaction of Fluid Pressure Penetration (FPP) was carried out in an iterative manual procedure at a temperature of $20^{\circ} \mathrm{C}$. This procedure is now automated and implemented through an APDL script, which adjusts the spring force at a macro-scale to maintain a consistent seal at elevated temperatures. Finally, using the Alicona Infinite Focus the surface form and waviness is measured, presented and modelled as $1 / 4$ symmetric over a macro to nanometer scale. It is clear the surface form also needs to be accounted for, something which the literature does not focus on.
\end{abstract}

Ali A. Anwar, e-mail: ali.anwarestrath.ac.uk

Yevgen Gorash, e-mail: yevgen.gorashestrath.ac.uk

William Dempster, e-mail: william.dempsterestrath.ac.uk

University of Strathclyde, Department of Mechanical \& Aerospace Engineering, James Weir Building, 75 Montrose Street, Glasgow G1 1XJ, UK 


\section{Introduction}

\subsection{Scope of research}

There are many commercially available valves which perform different functions. Valves can function as isolators, diverters, flow reversal prevention and reduce pressures within a service system. The service characteristics can range from fluid type, fluid characteristics, pressure, temperature, chemical resistance and finally operational and maintenance requirements (Smith and Vivian, 1995). Appropriate valve selection is dependent on complete knowledge of the required function and the service characteristics.

When choosing a valve it has been recommended to factor in the leakage since leak tightness has a direct effect on the operational and maintenance requirements (Zappe, 2004). Depending on the service, especially if the fluid is hazardous to humans or the environment, the leak tightness is of the highest interest. Regardless, for any service characteristic and function the leak tightness will have a direct effect on the overall pressure of the system over time, therefore the leak tightness is equitable to a direct cost in operations and maintenance.

As the operating pressure within a Pressure Relief Valve (PRV) reaches the set pressure, the sensitivity of the valve opening prior to reaching an equilibrium (set pressure $=$ operating pressure) increases. To be able to seal the valve up to $90 \%$ of the set pressure and higher requires research into the leak tightness of the valve. The PRV of particular interest is the STARFLOW P3 PRV manufactured by by Weir Power \& Industrial Division.

This research program was initiated to understand leak tightness of a metalto-metal contact of a PRV and take the early steps to model the leakage using computational solvers. A preliminary work package by Gorash et al $(2015,2014)$, predominantly of Finite Element Analysis (FEA), showed that the inner section of the metallic valve seat is subject to deformation due to a cyclic analysis. Gorash et al $(2015,2014)$ recommended that to pursue:

1. A 2D axisymmetric cyclic analysis of a PRV using Fluid Pressure Penetration (FPP) at an elevated temperature;

2. Create an ANSYS Advanced Parametric Language Script (APDL) to automatically account for macro and micro FPP;

3. Combine this all with a multi-scale model which accounts for surface roughness deformation and its effect on leak tightness.

This chapter will focus on a literature review and recommendation 1 and 2 from above. Originally the third point from above in the recommendations was going to be followed, however one of the main findings of the research program (after completing step 2) was that a vital surface finish quantity needed to be accounted for and had not been highlighted in the literature for metal-to-metal seals. This surface finish quality is known as the surface form and the measurements taken using the Alicona Infinite Focus are shown in this chapter. Within the literature the surface 
form is generally associated with flatness and an implicit assumption is made where the contacting surfaces are assumed "perfectly flat".

After researching this further it had been decided to account for surface form profile and waviness deformation using 3D 1/4 symmetry FEA which accounts for a micro to nano meter geometry. In the future this would then be connected to a Computational Fluid Solver (CFD) to quantify leakage of the valve due to surface form and waviness.

\subsection{Background information}

For the benefit of the reader who is unaware of either a PRV, its components or Surface Metrology, this short section will give a brief overview with respect to the research discussed.

\subsubsection{Pressure Relief Valve (PRV) - components and functionality}

Since only PRVs are considered for this project, it is vital to understand the components and functionality of a PRV. A schematic presentation is provided in the form of a classical ASME valve (see Fig. 1a) and DIN valve (see Fig. 1b). These have been chosen since they represent majority of spring-loaded PRVs available worldwide, which utilise metal-to-metal and seat-to-disc contact.

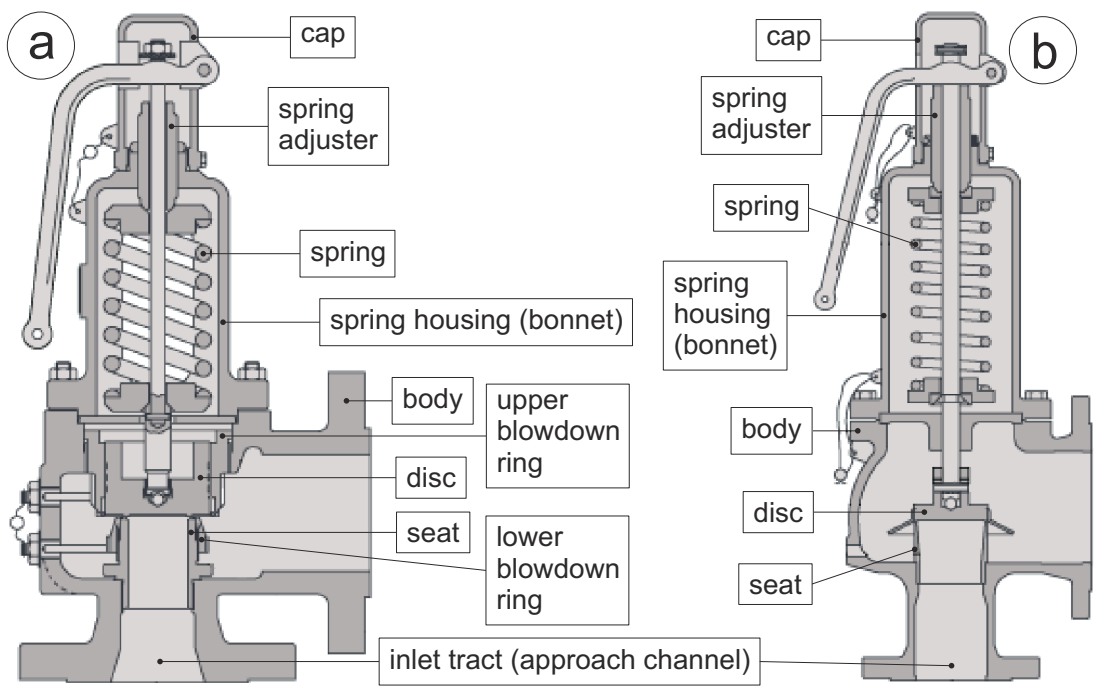

Fig. 1 Valve component schematic for typical (a) ASME and (b) DIN valves (Spirax Sarco, 2016) 
A PRV functions within a pressured system which is generally connected to either pressurised tanks or pipes. Its purpose is to release overpressure from a pressurised system which has exceeded its design pressure to ensure system safety and allow operations to continue. The valve is designed to release the fluid from the system to relieve pressure, autonomously.

As the system pressure increases the pressure in the inlet tract increases accordingly. The spring stiffness is set using an adjuster (or a compression nut depending on design) which results in a force being applied to the Seat via the Disc. This force will be known as the spring force $\left(F_{\mathrm{sp}}\right)$. The disc and seat are separate and only have a metal-to-metal contact, effectively acting as the seal. The valve is sealed at a pressure known as the "set pressure".

When the pressure in the system is greater than the set pressure - also known as over-pressure - then the force holding the disc down on the seat is outweighed, the disc lifts and the fluid enter into the secondary chamber and releases through the outlet tract. It is also important to note that the effective seat area also increases due to more of the disc being exposed to the inlet pressure when the valve seat is lifted due to the increased pressure.

\subsubsection{Metrology: surface finish}

If a material such as steel is cut and ground down to a smooth finish, it is important to understand what quality of finish is present. To the naked eye it may look to be flat and a smooth finish, however a different story can be told when viewed under magnification. Generally when viewed under magnification a chaotic surface is present. To measure this chaotic surface metrological techniques must be used.

Metrology is a core, long established scientific method of geometrical measurement. This topic is one of the three cores of the project since the understanding of surface finish and how we can quantify it is of great importance. For this research program there are 3 surface metrology concepts to introduce: Average Surface Roughness $\left(R_{\mathrm{a}}\right)$, Average Waviness $\left(W_{\mathrm{a}}\right)$, and Surface Form, as shown in Fig. 2.

Surface form is the shape that the surface takes when formed. This shape is usually distinguishable visually and then measured and displayed as a profile as seen in Fig. 2. If all the points along the surface form are considered and enclosed via an upper and lower boundary region, encapsulating all the points, the flatness can be attributed to the difference between the highest and lowest points within the region. The average waviness is a magnification of the surface form which accounts for irregularities that deviate from the mean surface represented by sinusoidal waves. The average spacing between the wave period is known $W_{\mathrm{sm}}$.

A further magnification of the waviness shows surface roughness which accounts for irregularities along the waviness profile and again is represented by sinusoidal waves. The average waviness and roughness is considered for this project. It is possible to model the surface using actual scanned profiles. 


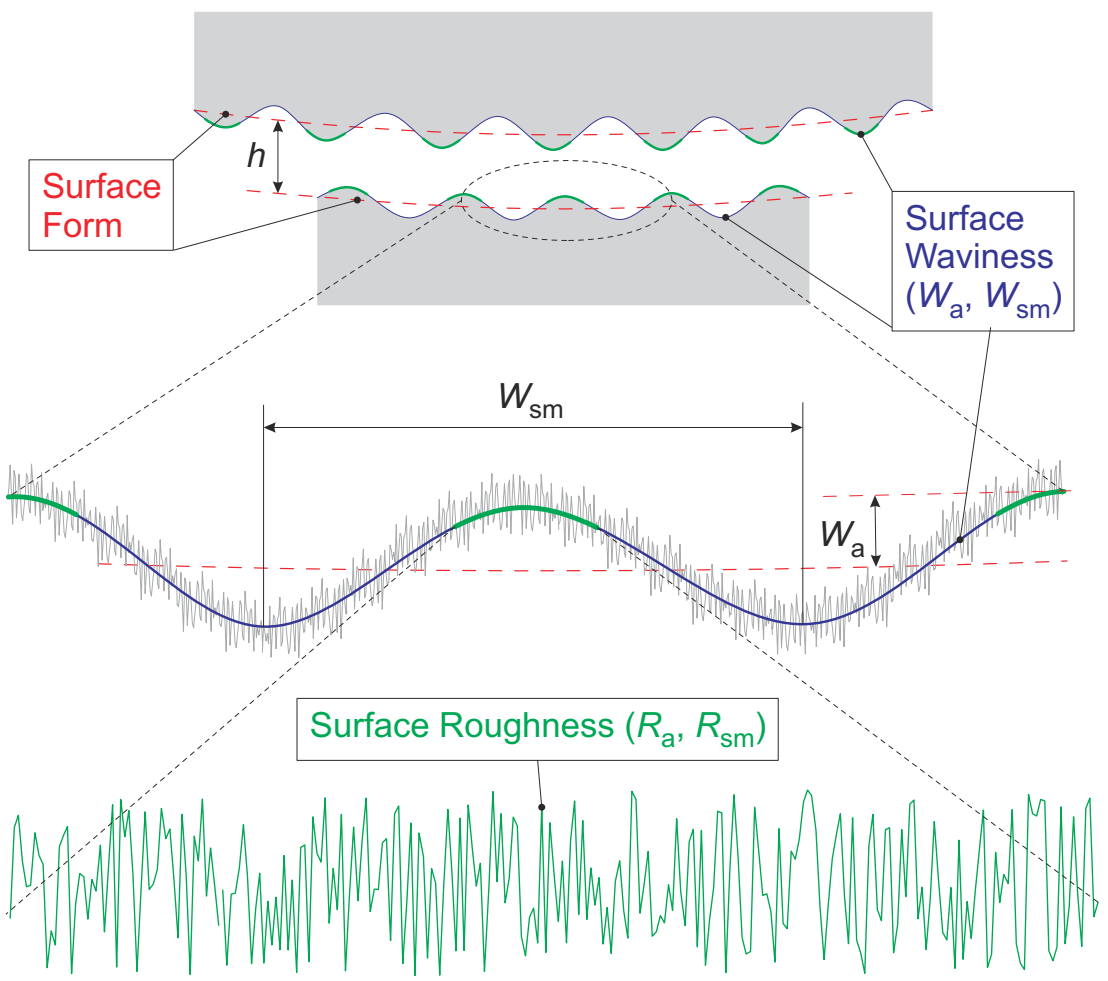

Fig. 2 Surface form, waviness and roughness depicted on two contacting surfaces separated by a gap size of $h$

\section{Literature review}

This section identifies the current understanding and technological knowledge of leak tightness of metal-to-metal contact PRV's. Within a PRV the seat and disc would be in contact and would constrain the fluid. Research in this field in direct relation to valves is scarce. However, inspiration can be drawn from relevant fields such as: metal-to-metal contact and gasket seals. When these contacting surfaces come in contact in parallel to each other a finite gap or path is present which is dictated by the surface finish such as: profile, roughness, waviness, flatness, etc. Subsequently if there is a driving internal pressure the fluid can pass through the path and exit the valve. It has been stated by Burmeister et al (1967) that the minimum leakage rate which can be obtained for 1 time seal applications is "less that $10^{-8}$ atmospheric $\mathrm{cc} / \mathrm{sec}$ of helium".

Previous work suggests that the leakage rate is either viscous laminar flow, molecular flow or, in the intermediate or transitional regime, or a mix of both. Assuming the non-contact area through the gap to be a finite length and the fluid to be isothermal and viscous compressible/incompressible, Poiseuille flow equations are utilised 
either for a circular cross section (Burmeister et al, 1967) or parallel plates. More recent work shows the development of fluid flow due to diffusion flux based on high to low concentration regions through the contacting surfaces using Fick's Law for incompressible isothermal fluids. The lineic flow rate characteristics which determines the gap height for both Poiseuille flow and diffusion are generally put into two characteristics: transmissivity $\boldsymbol{K}$ and diffusivity $\boldsymbol{D}$ (BHR Group Ltd., 2000; Mitchell and Rowe, 1969; Ledoux et al, 2011; Vallet et al, 2009; Geoffroy and Prat, 2004).

The true area of actual contact between two parallel faces is only a small fraction of the nominal area due to the aperture. To describe the path the fluid would take, the chaotic surface must be characterised. Methods to characterise the surface have been created by many authors such as the MOTIF procedure, self-affine fractal analysis and simplistic geometry. Recently this has been adopted into leak tightness projects to determine its effect on the gap height (Robbe-Valloire et al, 2001; Robbe-Valloire and Prat, 2008; Gagnepain and Roques-Carmes, 1986; Ganti and Bhushan, 1995).

The contact area is dependent upon the aperture of both surfaces in contact and the deformation magnitude is dependent upon the normal load applied and the effective surface hardness of the softer of the two materials. Depending upon the loading the surface aperture can become plastic in areas while the whole structure remains predominantly elastic. Taking this into consideration, the flow path will change depending on the load. Attempts have been made to analytically and computationally describe the surface roughness, elastic (using Herts theory by O'Callaghan and Probert (1987)), elastic-perfectly-plastic (refer to Man et al (2014)) and perfectlyplastic and rigid (using theory by Tsukizoe and Hisakado (1965) in Geoffroy and Prat (2004)) deformation and understand its effect on the gap height or aperture field.

To verify the leakage rate experimentally British, ASME and API, standards can be used. Recent experimental work by Haruyama et al (2013) and Geoffroy and Prat (2004) have shown promising methods of detecting and quantifying leakage and its link to the transmissivity $\boldsymbol{K}$ and diffusivity $\boldsymbol{D}$ values. More specific research into PRV leakage which detracts from surface finish has been conducted by Ritchie (1989) which examines the effect of misalignment of the valve and its effect on pressure drop. Computationally to model a whole seat and disc of a PRV with the surface roughness and waviness would be possible, but intensive and other techniques such as multi-scale modelling (Thompson, 2007b; Jackson and Streator, 2006) could be considered instead. Finally, the most recent development by Pérez-Ràfols et al (2016) is a computational model that is utilised to study the leakage through metal-to-metal seals accounting for both the waviness of the spiral groove and the surface roughness. Correlation between percentage real contact area and actual contact topology and leak rate was confirmed through numerical analysis.

\subsection{Leakage: fluid flow assumptions}

Depending on the service characteristics the fluid type and characteristics such as pressure, temperature and contaminants will vary. Generally high performance valves 
will be capable of withstanding compressible and incompressible Newtonian fluids which range from $-196^{\circ} \mathrm{C}$ to $-540^{\circ} \mathrm{C}$ and pressurised up to 440 bar. Assuming the valve has not opened and the seat and disc is in contact, only the surface deformations at a micro scale create an aperture field through which the fluid can escape out.

In previous studies on gaskets, valves and metal surface contacts, the fluid flux has been assumed to be laminar and either; viscous isothermal compressible/incompressible and equated using Poiseuille law $\boldsymbol{q}_{\mathrm{v}}$ (volumetric flow rate) per unit width in Eq. (1); or diffusive, equated using Fick's law $\boldsymbol{q}_{\mathrm{d}}$ (volumetric flow rate) per unit width in Eq. (2), as shown below:

$$
\begin{aligned}
& \boldsymbol{q}_{\mathrm{v}}=-\frac{\boldsymbol{K}}{\mu} \nabla p \\
& \boldsymbol{q}_{\mathrm{d}}=-\mathcal{D} \boldsymbol{D} \nabla c
\end{aligned}
$$

where $\mu$ is the viscosity, $p$ is the fluid pressure, $\mathcal{D}$ is the molecular diffusion coefficient and $c$ is the mass fraction of the species. $\boldsymbol{K}$ and $\boldsymbol{D}$ are respectively the transmissivity and diffusivity values. These allow the lineic flow rate characteristics to be described at the scale of the surface. Based on a parallel gap with a height of $h$ these terms can be described as:

$$
\begin{aligned}
\boldsymbol{K} & =\left\langle\frac{h^{3}}{12}(\boldsymbol{I}+\nabla \boldsymbol{b})\right\rangle, \\
\boldsymbol{D} & =\langle h(\boldsymbol{I}+\nabla \boldsymbol{b})\rangle,
\end{aligned}
$$

where $\boldsymbol{b}$ is the solution of the closure problem (Vallet et al, 2009).

Majority of authors have adopted a parallel gap (Mitchell and Rowe, 1969; Ledoux et al, 2011; Vallet et al, 2009; Geoffroy and Prat, 2004) rather than a circular cross section (Burmeister et al, 1967). This generalisation is more appropriate since the diameter of flow path does not need to be known, rather the separation between the contact surfaces is adequate. Also this is only applicable to asperities with local small slopes $l$, where $h \ll l$ or $l<10^{\circ}$ (Vallet et al, 2009). The connection between the transmissivity $\boldsymbol{K}$ and diffusivity $\boldsymbol{D}$ has been theoretically analysed by Geoffroy and Prat (2004) and they conclude that the dependence of the fluid transition in either $\boldsymbol{K}$ or $\boldsymbol{D}$ form is defined by both the gap size and applied load. The caveat with this theory is that a uniform gap height, surface form, waviness and roughness are present with a flat surface deforming it, which is implicitly applied for the latter.

Depending on the rarefaction of the fluid, it could also be in the transition or slip flow regime. This is likely since the surface roughness is at a micro-scale and therefore the gap height is also likely to be similar. This can be verified by calculating the Knudsen number and has been accounted for by Gorash et al (2014) in an analytical model which is an extension of the Poiseuille's Law for fluid flux through a parallel gap written as:

$$
q=\frac{h^{3}}{24 \mu R T}\left[P_{0}^{2}-P_{1}^{2}+12 \frac{2-\sigma_{a}}{\sigma_{a}} K n_{1} P_{1}\left(P_{0}-P_{1}\right)\right]\left|\frac{P_{0}^{2}-P_{1}^{2}}{P_{1}}\right|,
$$


where $\mu$ is the accommodation coefficient, $R$ is the gas constant, $T$ is the temperature and $\mathrm{Kn}_{1}$ is the Knudsen number at the outlet. The second more subtle assumption here is that the micro fluid flow is based on the outlet not the inlet.

There has been a further modification of this equation to account for chocked mass flow rates at the exit of the microchannel by Chong (2006):

$$
\dot{m}=\frac{h^{3}}{24 \mu R T}\left(1+12 \frac{(2-\mu)}{\mu} \frac{\sigma_{a}}{P_{1} h} \frac{16}{5} \sqrt{\frac{k T}{2 \pi m}}\right) .
$$

where $\pi=3.14$. This equation is questionable since for chocked conditions for a gas compressibility would have to be considered while Xie's equation does not.

The original form of Eq. (5) was proposed by Arkilic et al (1997) who also defined the pressure distribution across the gap to be:

$$
\frac{P(x)}{P_{1}}=\left\{\left(6 \mathrm{Kn}_{1}+\frac{P_{0}}{P_{1}}\right)^{2}-\left[\left(\frac{P_{0}^{2}}{P_{1}^{2}}-1\right)+12 \mathrm{Kn}_{1}\left(\frac{P_{0}}{P_{1}}-1\right)\right]\left(\frac{x}{L}\right)\right\}^{\frac{1}{2}}-6 \mathrm{Kn}_{1},
$$

which has shown very good agreement with experimental results for subsonic flows.

\subsection{Representation of surface roughness at micro-scale and its effect on fluid flow path}

Micro-scale geometry of a surface profile is chaotic in nature making it important to be able to represent the area in an effective form since this has a direct effect on the gap height, $h$. There are methods available which make it possible to represent the surface roughness of a model at a micro-scale level. These can be in the form of generic surfaces such as a sinusoidal waves (Geoffroy and Prat, 2004; Pérez-Ràfols et al, 2016) or vibrational Eigen modes (Ledoux et al, 2011) or wedges (Mitchell and Rowe, 1969). There are more analytical methods based on the surface available such as the sum surface (Robbe-Valloire et al, 2001), MOTIF procedure (Robbe-Valloire and Prat, 2008) and fractal analysis (Vallet et al, 2009; Gagnepain and RoquesCarmes, 1986; Ganti and Bhushan, 1995) which all have benefits and limitations. The benefits and limitations are discussed below and its effect on the gap size.

The sum surface allows the direct analysis of two contacting surfaces. This technique is used by many authors (O'Callaghan and Probert, 1987) and based upon a theory created by Tsukizoe and Hisakado (1965), which states, it can be assumed that, "the contact between two rough surfaces can be regarded as the equivalent to the contact between an imaginary rough surface having an appropriate effective topography and a perfectly flat surface" and "the contacting asperities deform in an ideal plastic manner so that, providing no interference from neighbouring asperities occurs and that work hardening does not take place" as that shown in Fig. 3. Essentially the flat surface is assumed rigid perfectly-plastic surface. These are accepted 
and applied assumptions in references (Mitchell and Rowe, 1969; Ledoux et al, 2011; Robbe-Valloire et al, 2001). The main limitation with the sum surface technique is that the actual surface has to be measured physically. A further limitation is that representation of the surface is generally in a 2D format and an "effective" gap size, $h$, has to be calculated and is generally based on an average values as demonstrated by Mitchell and Rowe (1969).

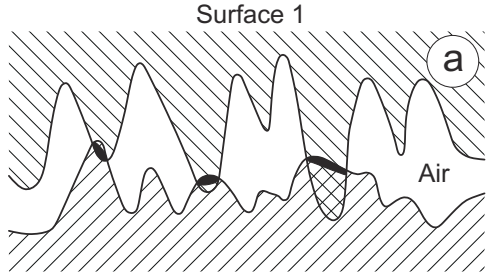

Surface 2 (harder than Surface 1)
Equivalent rough surface

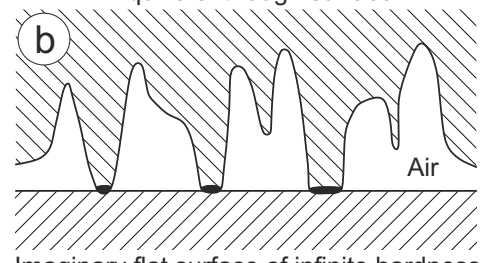

Imaginary flat surface of infinite hardness

Fig. 3 Illustration of (a) sum surface technique, wich is used to generate of (b) equivalent rough surface with black areas indicating micro-contacts, after O'Callaghan and Probert (1987)

More recently, the surface roughness of both lapped and sand blasted surfaces has been represented as self-affine fractal surfaces combined with the sum surface technique contacting a rigid-perfectly plastic flat surface (Vallet et al, 2009). By using fractal analysis the self-affine fractal surface is based on two parameters and is created using a power law. Using this technique the surface roughness can be modelled in $3 \mathrm{D}$, representing the whole aperture field. $2 \mathrm{D}$ representation can be created using this technique but an "effective gap size", $h$, would have to be employed when calculating leakage rate. Vallet et al (2009) show good agreement when comparing the fractal surface representation to the "real" surfaces for the lapped surfaces. This shows that for lapped surfaces self-affine fractal surfaces can be used to generically replicate surfaces and represent the aperture field. The main limitation of this method is that the mathematics is intensive and requires the use of computational programs such as MATLAB. By modelling the whole aperture field all possible fluid flow paths can be represented and more accurate gap sizes through the valley and peaks can be calculated.

\subsection{Micro material deformation of rough surfaces and its effect on fluid flow path}

When two surfaces each with their own unique roughness come into contact, the actual contact area is much less than the nominal area. The magnitude of the contact area is dependent on the load applied. So, the accurate deformation of the surface roughness's is of great importance since the voids between the surface roughness's is the gap size (2D) or aperture field (3D) through which the fluid will flow. Also 
a small change at a micro scale will reverberate in a larger change over a macro scale. Theory by Tsukizoe and Hisakado (1965) essentially assumes the flat surface is rigid and the summed surface is perfectly-plastic and as said these are accepted and applied assumptions in references (Mitchell and Rowe, 1969; Geoffroy and Prat, 2004; Robbe-Valloire et al, 2001).

Using slip line field theory, Mitchell and Rowe (1969) have incorporated the effects of the perfectly-plastic isotropic deformation structural response of twodimensional wedges to represent the surface roughness in contact with a rigidperfectly-plastic flat surface which is based on the theory discussed above. The slip line theories main limitation is that it is used to model plastic deformation in plain strain only for a solid represented as a rigid-perfectly-plastic flat surface (University of Cambridge, 2004). It is shown that for all contact pressures there is a specific deformed wedge angle found and crucially there is a point at which a maximum leakage rate for specific wedge angle over the seat length. The limitations of the findings are concurrent with the fluid flow assumptions about the gap size and the simplified representation of the surface roughness.

Assuming a simplistic, but effective sinusoidal shape geometry to represent the surface roughness in contact with a flat surface (Geoffroy and Prat, 2004; PérezRàfols et al, 2016), it is shown that as the load on the gasket is increased, the incompressible fluid flows from a radial direction, to a circumferential spiral fluid flow through the valleys as shown in Fig. 4. It is also shown that there is a very small region over which the transition from circumferential to radial (or vice-versa) occurs and the diffusive and viscous flows are mixed. It is concluded that the radial leakage (which is related to the transmissivity) is of most critical since it is very sensitive to the gap size. However, this theory can only be valid for surfaces which depict a predominantly sinusoidal shape contacting a flat face.
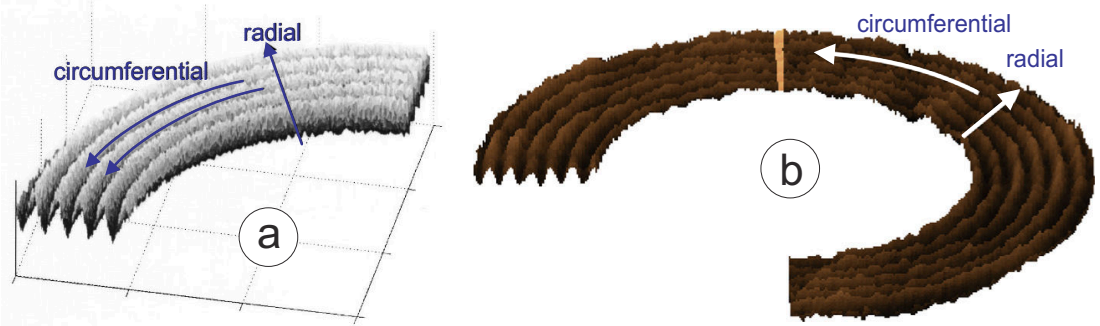

Fig. 4 Schematic illustration of the crest and valley sinusoidal fluctuations indicating radial and circumferential direction used by (a) Geoffroy and Prat (2004) and (b) Pérez-Ràfols et al (2016)

Another analytical technique which accounts for elastic deformation is the Hertz theory (O'Callaghan and Probert (1987)). The Hertz elastic deformation theory is only applicable for surfaces with purely spherical aperture contacting shapes. It is employed by Man et al (2014) for two 3D random rough surfaces in contact. As the two rough surfaces come into contact and deform due to the loading applied, the 
leakage path through the aperture field is dictated by the largest gap from one end of the specimen to the other and is calculated using a "recognition algorithm" (see Fig. 5 for details). This fluid flow path recognition is a simplistic, but effective theory to allow one to understand if the micro-contact under specific loads will either leak or not for a material.
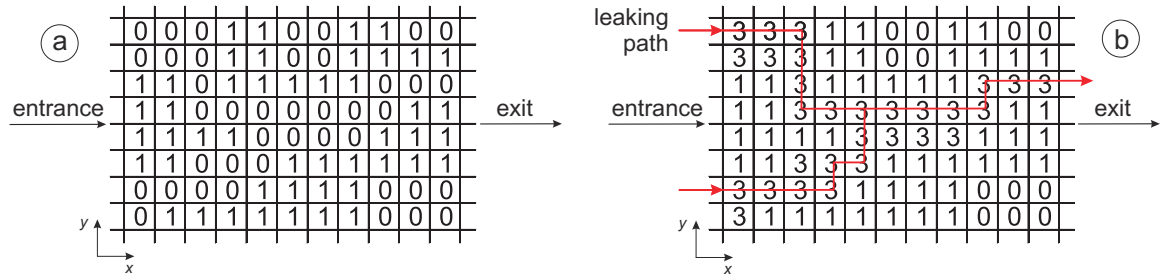

Fig. 5 Recognition algorithm diagram of leak path identification where 0 is no gap and 3 is the fluid flow path: (a) contacting state and (b) leaking path, after (Man et al, 2014)

\subsection{Macro scale deformation and its effect in fluid flow path}

Using FE-code ANSYS, Gorash et al $(2015,2014)$ have shown that at a macro-scale the contact length of the seat and disc of a PRV is reduced and is further exasperated due to cyclic opening and closing of the valve. Gorash et al $(2015,2014)$ assumed the contact force to be normal to the face of the seat and disc modelled as 2D. Using elements PLANE 183 (for both the seat and disc model), COMBIN14 (spring), CONTA172 (seat contact) and TARGE169 (disc contact) and assuming that for a gas and liquid the fluid flow pressure acting on the seat and disc is parabolic and linear respectively, they have shown that the once the spring preload and the internal set pressure is applied, the contact edges of the disc become plastics for a monotonic material response. This plastic response of the seat is exasperated towards the middle of the disc when cyclic material response is considered. This essentially means the fluid flow path is increased, while effective contact area and length would reduce meaning a higher leakage rate.

\subsection{Experimental leakage rate}

One of the earliest collection of advanced studies addressing testing and analysis of PRVs performance was compiled by Singh and Bernstein (1983). The book covers the topics of test facilities design, safety valve experiments, analysis of PRVs performance, and loads on discharge piping. The state-of-art approach to calculate the leakage rate of a PRV is based on recent international standards, e.g. ASME 
(2014); BSI (2013); API (2014). This method requires the PRV to be set to $90 \%$ of its set pressure using a gas. The outlet of the PRV is closed off with a pipe attached to expel the increase in pressure (i.e. leakage) in some water in the form of bubbles. The leakage has to be less than a specified amount for it to be used in-service.

Based on the average surface roughness, there have been attempts to relate this to the leakage rate through a gasket. Haruyama et al (2013) created an experiment which quantified the leakage rate of helium through a bolted flange with a new gasket placed between. They concluded that the leakage rate is highest for rough surfaces of $R_{\mathrm{a}}=3.5 \mu \mathrm{m}$ when a low load force is applied. When a maximum of $400 \mathrm{MPa}$ of force is applied on the flange then leakage rate is the least and is similar for all $R_{\mathrm{a}}$ 's being $1.5,2.5$ and $3.5 \mu \mathrm{m}$. However, the material properties of the gasket and the flange are not known and so links between the material deformation and leakage is difficult to comment on.

Another method used by Marie and Lasseux (2007) allows quantification of leakage flow of solvents at a micro or nano-scale through a rough metal contact for both viscous and diffusive fluid flow separately for contact pressures up to $700 \mathrm{MPa}$. Using the leakage results Equations (1)-(4), they have managed to find the diffusive and viscous properties from which the effective gap size has been estimated.

\subsection{PRV specific issues relating to leakage}

Now that an understanding of the work currently completed on micro deformation and its effect on leakage has been analysed it is important to consider factors which are unique to a PRV which could also cause it to leak.

Depending on the design of the valve, one issue which has been highlighted is that the guide pin can be displaced easily which causes the seat to rotate or displace. This rotation/displacement of the seat causes the valve to leak and subsequently the set pressure decreases. Ritchie (1989) examined this issue and created an analytical model to understand the reduction of seat pressure due to the misalignment angle of the seat. Assuming the valve leaks only when the set pressure has been reached, it was shown that for a disc with radius of $8.47 \mathrm{~mm}$ and $155 \mathrm{~N}$ of applied force on the seat, the set pressure (100 psi) decreases by $10 \%$ for a misalignment of 1.225 degrees for the seat.

\subsection{Summary and discussion}

As it has been shown, previous analytical work accounts for the gap height either in the form of $h$ or $h^{3}$ for a parallel gap. This is mainly been accounted for only laminar viscous incompressible/ compressible or diffusive flow through the aperture field, with more recent work in accounting for the rarefaction of the flow. However, the parallel gap assumption is limited to small asperities $h \ll l$ and there has to be an 
"effective" height used for a 2D surface model which is geometrically represented as simple surfaces. While for 3D surface models computer programs such as MATLAB or equivalent can be used to model lapped surfaces with high accuracy as self-affine fractal surfaces, but are extensive.

In reality Tsukizoe and Hisakado (1965) and the slip-line theory is not completely valid for multiple asperity contacts demonstrated by the experiment conducted by Uppal and Probert (1972). They showed that for a multiple asperity surface in contact with a harder flat surface, under a high load the shallower valleys do rise $(0.1 \mu \mathrm{m}$ $0.3 \mu \mathrm{m}$ ) while deep valleys do not, while Tsukizoe and Hisakado (1965) theory considers no movement in the valleys. So, there is an element of elastic behaviour and plastic strain hardening occurring which would have to be considered.

Instead of analytical techniques to describe the deformation of two rough surfaces, FEA programs such as ANSYS could be utilised to describe elastic perfectly plastic deformation of the interface as shown by Megalingam and Mayuram (2012) using actual 3D or 2D scanned surfaces. There is other literature particularly by Thompson (Thompson, 2007b; Thompson and Thompson, 2010b,a; Thompson, 2007a, 2011), which gives further guidance on multi-scale modelling and optical measurements of the surface aperture which is then transferred into ANSYS. The FEA would require some form of verification of the surface deformation accuracy, but if achieved, this will allow a more accurate representation of the fluid flow path.

This could be taken further by modelling the surface as a representative surface using summing technique, self-affine fractal surface or MOTIF procedure, versus, the actual surface in FEA and see the difference in the contact area.

A theory created by Geoffroy and Prat (2004) tries to link the diffusive and transmissive fluid flow to either radial or circumferential, but has not been verified and is only applicable to predominant sinusoidal shaped surfaces in contact with a flat surface, i.e. gaskets. Recenlty, Pérez-Ràfols et al (2016) have extended the work of Geoffroy and Prat (2004) by using the summing technique material considerations for a composite elastic modulus (i.e. the effective elastic modulus of the joint) and used a reltaive size of the whole model, rather than modelling the whole surface. However, in doing so, there is still the implicit assumption made by Pérez-Ràfols et al (2016) that there is no deviation in the surface form, which may be appropriate for gaskets, but not for this program as will be discussed later in section 4 .

Gorash et al $(2015,2014)$ have shown that there is a deformation at a macro scale due to the spring force and the pressure of the fluid, which has to be considered to begin. Their work has shown the contact is not uniform between a seat and disc of a PRV rather; it begins and ends within the seat length. So there is a need to understand how the macro and micro contact areas link to give the actual contact area.

The disc rotation on the seat causing leakage maybe more of a design problem rather than a research based problem. The reason for this is that there are clearances prevalent throughout the seat and disc allowing this motion to occur. Also it is understood that the spring force under compression may not be perpendicular to the compression axis of the spring.

Further investigations would be required to understand the effect of grain boundaries on the deformation of surface roughness at a micro scale. 


\section{Effect of high temperature on structural behaviour of metal-to-metal seal in a pressure relief valve}

This section focuses on the structural behaviour of the metal-to-metal contact seal in a PRV when the material, AISI type $316 \mathrm{~N}(\mathrm{~L})$ steel, behaves and reacts as it would when exposed to a higher temperature. In this case the temperature of interest is $538^{\circ} \mathrm{C}$ (maximum operating temperature for the investigated valve) and the fluid being a gas i.e. air. The maximum operating pressure supported by the valve in question is $18.6 \mathrm{MPa}$. The initial work conducted by Gorash et al $(2015,2014)$, will also be discussed in this section.

To study these specific effects of temperature and pressure a finite element analysis is undertaken using ANSYS Parametric Design Language (APDL) script to account for Fluid Pressure Penetration (FPP) through the contact gap. This APDL script allows for pressure between the contact gap to be accounted for sufficiently and automatically adjusts the force retraining the valve. Ultimately this allows for a cyclic analysis of the valve opening and closing with FPP accounted for. Previously, Gorash et al $(2015,2014)$ had to manually account for FPP for every time step until the opened. This meant lengthy solving times.

This research builds upon the work conducted previously (Gorash et al, 2015, 2014). In particular, this research advances in the structural model by analysis conducted at an elevated temperature; with a more accurate material model to consider viscoplastic deformation at high temperature; by creating an APDL script to automatically account for the FPP migration; and adjustment of the spring force to maintain the desired set pressure.

\subsection{Seat contact configuration}

The PRV is simplified into three 2D axisymmetric basic parts: a cylindrical nozzle, which is in contact with a disc (representing the valve seat on top), which is preloaded by a compressed linear spring. This concept is represented in Fig. 6 . The effects on the bell-housing and any other parts such as the nozzle ring are not of interest as it is assumed they do not have any effect on the structural behaviour of the seal.

The compression force of the spring is transferred directly to the disc and then to the seat due to the contact. It is this compression force and quality of the contact which maintains the seal up to the set pressure. For this analysis it is assumed that the contact is geometrically uniform. From the study by Gorash et al $(2015,2014)$, it has been shown that due to FPP the internal contact between the disc and seat significantly deforms due to plastic deformation even at room temperature. The pressure that the FPP attributes to the disc and seat in the contact zone will be known henceforth in this report as the macroscopic pressure distribution.

In reality the contact between the faces of the seat and disc are not uniform, especially at a micro scale, where surface form, waviness and roughness contribute to 


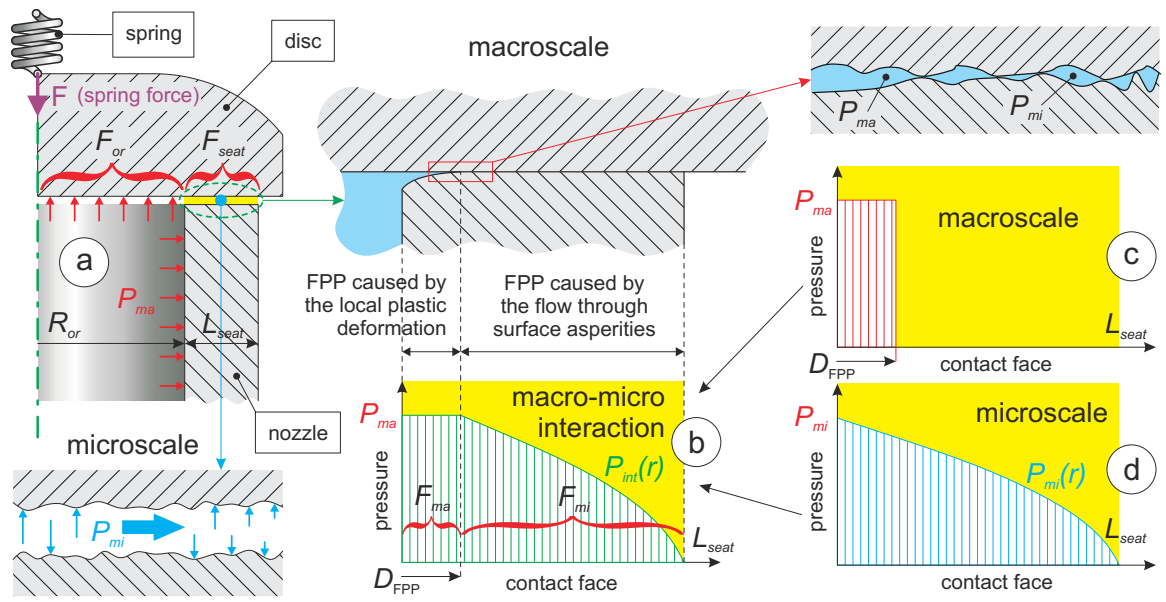

Fig. 6 Concept of seat contact configuration in the contact area of metal-to-metal seal considering FPP (fluid pressure penetration)

the leakage. In this case it will be assumed that there is a degree of surface roughness between the contacting faces. To account for this the fluid pressure attributed to the surface roughness of the contacting faces in the gap, Müller and Nau (1998) had shown that the pressure drop across a sealed gap for a compressed fluid can be represented using a power-law function dependent on distance as:

$$
P(x)=P_{1}\left[1-\left(1-\beta^{2}\right) \frac{x}{L}\right]^{n},
$$

where $L$ is a length of a seal gap; $P_{1}-$ internal pressure and $P_{2}$ - external pressure; so the pressure ratio is $\beta=P_{2} / P_{1}$ and $n$ is a power law exponent, which is dependent on the type of fluid, e.g. $n=0.5$ for gas and $n=1$ for liquid. Henceforth in this report this pressure distribution will be related to as the microscopic pressure distribution. Equation (8) can be extended further by slightly changing the mathematical representation to be aligned with the contact gap in question in a mathematical form as:

$$
P(r)=P\left[\frac{r_{\mathrm{out}}-r}{r_{\mathrm{out}}-r_{\mathrm{FPP}}}\right]^{n},
$$

where $P$-internal pressure, $r_{\text {out }}$ - outer radius of the contact area, $r$-inner radius of the contact area, $r_{\mathrm{FPP}}$ - radius of FPP. This micro pressure distribution is formulated in this manner to account for the maximum FPP point travelled in the contact zone. Integrating Eq. (9) by $r$ over the length of the valve seat $\left(L_{\text {seat }}=r_{\text {out }}-r_{\text {in }}\right)$, an average value of the pressure within the micro pressure distribution is obtained as

$$
\bar{P}=\frac{P}{1+n} .
$$


Therefore, the force required by the spring to maintain the required set pressure between the seat and disc is an accumulation of the operating pressure up to the internal office, macro and micro pressure distribution multiplied by the associated areas. Hence the spring force can be represented in the following form:

$$
\begin{aligned}
& F_{\mathrm{sp}}=F_{\text {orf }}+F_{\text {macro }}+F_{\text {micro }} \Rightarrow \\
& F_{\mathrm{sp}}=P \pi r_{i n}^{2}+P \pi\left(r_{\mathrm{FPP}}^{2}-r_{i n}^{2}\right)+P \pi\left(\frac{1}{1+n}\right)\left(r_{\mathrm{out}}^{2}-r_{\mathrm{FPP}}^{2}\right) .
\end{aligned}
$$

If $n=0.5$ for a gas then:

$$
F_{\mathrm{sp}}=P \pi\left(\frac{2}{3} r_{\mathrm{out}}^{2}-r_{\mathrm{FPP}}^{2}\right)
$$

Alternatively, this can be expressed in terms of spring displacement $\Delta_{\mathrm{sp}}$ :

$$
\Delta_{\mathrm{sp}}=\frac{P \pi}{K}\left(\frac{2}{3} r_{\mathrm{out}}^{2}+\frac{1}{3} r_{\mathrm{FPP}}^{2}\right) .
$$

\subsection{FEA modelling and APDL script}

The numerical study is conducted using academic FE-code ANSYS 16.0. The three components, cylindrical nozzle, disc and spring are all simplified into a $2 \mathrm{D}$ axisymmetric, elastic-plastic model, as shown in Fig. 7. The model is set-up as a quasi-static structural analysis allowing the valve to open and close over 100 cycles.

As shown below, the spring is modelled using a COMBIN14 (2-node longitudinal linear spring-damper) finite elements (FEs). A vertical displacement of $\Delta_{\mathrm{sp}}$ is applied to compress the spring. As previously described the displacement $\Delta_{\mathrm{sp}}$ is proportional to the sealing set pressure, which as previously elaborated is due to the internal pressure and the macro-micro pressure distribution within the contact area. The spring is connected to the kinematic coupled nodes at the top of the disc. This is to ensure that the vertical force associated with the spring is distributed evenly and vertically down the disc.

The disc and seat are both constructed of PLANE183 (8-node axisymmetric structural solid) FEs with an internal pressure, $P$, placed on the inside and a fixed boundary constraint placed on the outside near the bottom of the seat (i.e. the connection to the outer valve body). The pressure, $P$, is ramped up with an average pressure change rate of $r_{\mathrm{pr}}=0.744 \mathrm{MPa} / \mathrm{s}$ in an incremental manner until the set pressure of 18.6 MPa is reached and then incrementally reduced to zero. This accounts for 1 cycle of the valve opening and closing.

The contact pair is made up of CONTA172 (2D 3-node surf-surf contact \{for disk ) and TARG169 (2D 3-node target \{for seat\}). The internal contact of the seat and disc is the associated starting point for the FPP feature and is allowed to penetrate along the full contact length. This FPP feature allows pressure to be associated with 


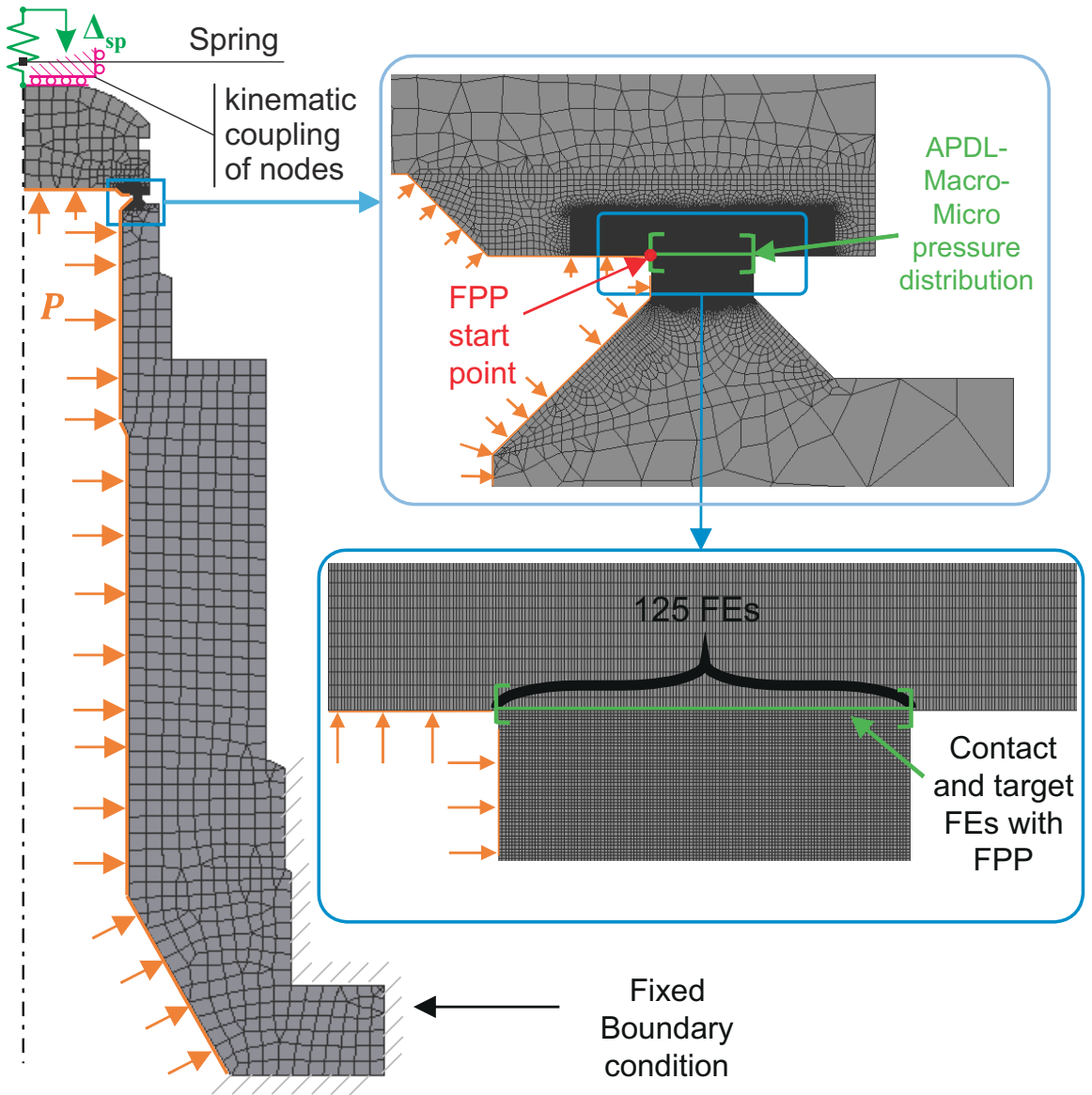

Fig. 7 FE model of the valve seat and disc, with a detailed model of the contact zone, boundary conditions and loadings

changing contact conditions, i.e. as the seat and disc deforms a gap is created and it will have the associated pressure applied in it automatically. As the valve ramps up in pressure and cycles open and close, it is expected for the FPP to migrate along the contact length. To account for the micro pressure distribution with respect to the FPP migration point an APDL script is required, so that the macro and micro pressure is applied correctly.

To ensure the FPP is captured accurately a high resolution of contact points are created between the seat and disc (125 FEs in the contact region). In total there are 16404 elements and 49939 nodes. For further information specific to element types please refer to ANSYS ${ }^{\circledR}$ Help (2013). 


\subsection{APDL script $r_{\mathrm{FPP}}$ retrieval and apply}

As the pressure incrementally increases, the FPP through the contact between the disc and seat increases gradually until the pressure is either not high enough to penetrate further or the deformation of the seat/disc reduces not allowing further penetration. The location point of the $r_{\mathrm{FPP}}$ is important to allow accurate micro pressure distribution to be applied and hence an accurate spring displacement $\Delta_{\text {sp }}$. To capture this migration of the $r_{\text {FPP }}$ location across the seat and disc an APDL script is required as shown in Fig. 8.

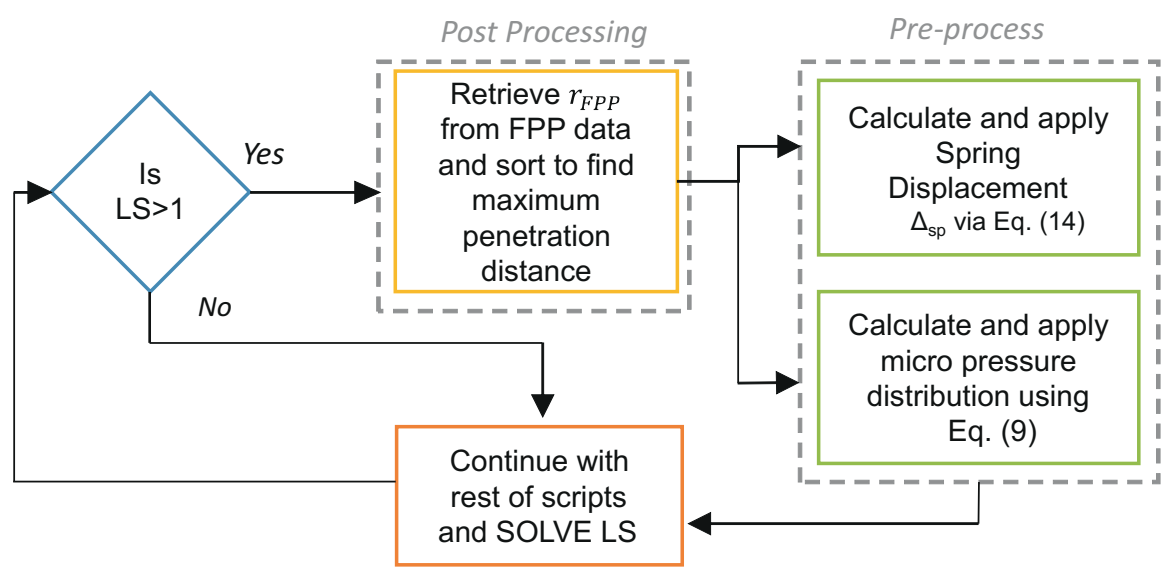

Fig. 8 APDL script flowchart. Beginning at the decision, and then moving though post-processing, pre-process and then returning to solve the problem until the next LS. After which this loop repeats until the last LS.

Figure 8 is a flowchart of the script which activates after the first Load Step (LS) has solved. The script retrieves the FFP contact data produced from the previous LS from the post processor. It then sorts the data out to find the maximum FPP location across the seat and disc. This data point is saved as $r_{\mathrm{FPP}}$ and the script instructs the ANSYS program to enter the pre-process (/SOLU) state and adjust the spring displacement and micro pressure distribution using Eq. (14) and Eq. (10) respectively. The micro pressure distribution is also applied only across location $r_{\mathrm{FPP}}$ to $r_{\text {out }}$. Once the post-process and pre-process stage is complete the program continues with any other scripts and solves for that LS. This process is restarted at the beginning of the next LS until all the LS's are solved.

\subsubsection{APDL restart bug}

The main challenge to overcome with this script was a bug which is present in ANSYS workbench 16.1. This bug is related to restart controls ("rescontrol"). After 
creating a new APDL script in the "Outline tree" the user has the option to select which LS the script is to be activated in via "Step selection mode". Due to the nature of the FPP, the script would have to be activated each LS. Naturally, the restart control APDL script should be set to activate for every LS. However, doing this causes the program not to restart with the new $r_{\text {FPP }}$ after every LS. Instead it would continue on with solutions found in the first LS. As a workaround solution for this bug, the user has to select "First" LS in "Step Selection mode" to ensure the restart controls work for each LS. This issue has been highlighted with ANSYS technical support.

\subsection{Material model}

The critical components of the PRV (nozzle and disc) are manufactured of the steel AISI type $316 \mathrm{~N}(\mathrm{~L})$ due to optimally appropriate mechanical properties of this steel grade. AISI type $316 \mathrm{~N}(\mathrm{~L})$ stainless steel has been used within the power-generating industry since the early 60's of 20th century. Commonly used in superheater piping, pressure vessels, heat exchangers and other components exposed to high temperatures of $650^{\circ} \mathrm{C}$ as indicated in previous work (Gorash et al, 2015, 2014). The mechanical characteristics of the steel AISI type $316 \mathrm{~N}(\mathrm{~L})$ makes it an optimal material for a valve seat which is expected to undergo high local contact stresses, corrosion-fatigue conditions and possible high-temperature exposure.

Mechanical properties of the steel AISI type $316 \mathrm{~N}(\mathrm{~L})$ in the range of $20-700^{\circ} \mathrm{C}$ show significant temperature dependence (Gorash et al, 2012). Available stress-stain experimental data and its fitting by elastic-perfectly-plastic (EPP) and RambergOsgood (R-O) material models were discussed by Gorash et al $(2015,2014)$. Compared to martensitic and ferritic steels, austenitic grades including type 316 have lower yield stress $\sigma_{\mathrm{y}}$, but higher rupture ductility. This complies with experimental observations at room and high temperatures, which confirm that the material behaviour of the steel AISI type $316 \mathrm{~N}(\mathrm{~L})$ is viscous and rate-dependent (Hyde et al, 2010). Thus, an accurate description of the plastic deformations with a unified viscoplasticity model (Chaboche, 2008) is essential to address structural integrity and operation issues.

In the previous study (Gorash et al, 2015, 2014), viscoplastic material behaviour of the steel AISI type $316 \mathrm{~N}(\mathrm{~L})$ was simplified to rate-independent plasticity neglecting viscous effects. Available monotonic and cyclic stress-strain curves were fitted by the R-O equation and incorporated through the Multilinear Kinematic Hardening (MLKH) model in ANSYS. Since the dynamic effects have been neglected, the PRV operation was assumed to be quasi-static for FE-simulation in ANSYS.

Consideration of viscoplastic effects for FEA in current work requires the mechanical material properties and Chaboche material constants at a temperature of $538^{\circ} \mathrm{C}$. These values are derived by simple interpolation using the experimental data by Hyde et al (2010) available for $300,500,550$ and $600^{\circ} \mathrm{C}$. In order to obtain constants for $T_{\mathrm{i}}=538^{\circ} \mathrm{C}$, the constants at lower $T_{1}=500^{\circ} \mathrm{C}$ and upper $T_{\mathrm{u}}=550^{\circ} \mathrm{C}$ neighbouring temperatures are used. The interpolation is done by using the weight- 
ing coefficients (lower and upper), which define the proximity of the interpolated temperature to the neighbouring temperatures:

$$
w_{1}=\frac{T_{\mathrm{u}}-T_{\mathrm{i}}}{T_{\mathrm{u}}-T_{1}} \quad \text { and } \quad w_{\mathrm{u}}=\frac{T_{\mathrm{i}}-T_{1}}{T_{\mathrm{u}}-T_{1}} .
$$

In this case, the weighting coefficients take the values of $w_{1}=0.24$ and $w_{\mathrm{u}}=0.76$. In general, the following condition should be satisfied for the temperature:

$$
T_{\mathrm{i}}=T_{1} w_{\mathrm{l}}+T_{\mathrm{u}} w_{\mathrm{u}} .
$$

Equation (16) is used to identify all the material constants for AISI type $316 \mathrm{~N}(\mathrm{~L})$ steel at $538^{\circ} \mathrm{C}$ using the constants at $500^{\circ} \mathrm{C}$ and $550^{\circ} \mathrm{C}$ (Hyde et al, 2010), which are reported in Table 1 and required for implementation of FEA in ANSYS.

Table 1 Material constants for Chaboche model for AISI type $316 \mathrm{~N}(\mathrm{~L})$ steel at $538^{\circ} \mathrm{C}$ interpolated from constants at $500^{\circ} \mathrm{C}$ and $550^{\circ} \mathrm{C}$ (Hyde et al, 2010) using Eqs (15) and (16)

\begin{tabular}{c|cc|cc|cccc|cc}
\hline $\begin{array}{c}T \\
{ }^{\circ} \mathrm{C}\end{array}$ & $\begin{array}{c}k \\
\mathrm{MPa}\end{array}$ & $\begin{array}{c}E \\
\mathrm{GPa}\end{array}$ & $b$ & $\begin{array}{c}Q \\
\mathrm{MPa}\end{array}$ & $\begin{array}{c}a_{1} \\
\mathrm{MPa}\end{array}$ & $C_{1}$ & $\begin{array}{c}a_{2} \\
\mathrm{MPa}\end{array}$ & $C_{2}$ & $\begin{array}{c}Z \\
\mathrm{MPa} \cdot \mathrm{s}^{1 / n}\end{array}$ & $n$ \\
\hline 500 & 32.5 & 145.54 & 33.35 & 30.41 & 94.6 & 6472.6 & 113.3 & 979.91 & 175 & 10 \\
538 & 31.36 & 142.29 & 31.56 & 28.43 & 88.29 & 6827.06 & 114.44 & 963.02 & 173.48 & 10 \\
550 & 31 & 141.26 & 31 & 27.8 & 86.3 & 6939 & 114.8 & 957.69 & 173 & 10 \\
\hline
\end{tabular}

In order to conclude about the influence of high temperature on cyclic deformation of the valve seal, the material constants for the Chaboche model are also required for $20^{\circ} \mathrm{C}$. Since the experimental stress-strain curves are available only for a single strain rate value, the rate-independent variant of the Chaboche model is used. The identification of corresponding constants is done using the fitting procedure suggested in previous work (Gorash and MacKenzie, 2014). This procedure comprises the initial smoothing of the cyclic stress-strain data by the R-O model and subsequent estimation of the kinematic constants using the Solver add-in of Microsoft Excel. The smoothed cyclic stress-strain data is fitted by the following equation for stress amplitude $(\Delta \sigma / 2)$ and plastic strain amplitude $\left(\Delta \varepsilon^{\mathrm{p}} / 2\right)$ :

$$
\frac{\Delta \sigma}{2}=\sum_{i=1}^{N} \frac{C_{i}}{\gamma_{i}} \tanh \left(\gamma_{i} \frac{\Delta \varepsilon^{\mathrm{p}}}{2}\right) .
$$

The number of kinematic back-stresses is increased to five $(N=5)$ in order to incorporate the mixed softening-hardening character of plastic deformation observed during cyclic response. The corresponding values of the kinematic constants $\left(a_{1}-a_{5}\right.$ and $C_{1}-C_{5}$ ) for the Chaboche model are reported in Table 2. The next step is the identification of isotropic constants $(k, b, Q)$ for the Chaboche model (see Table 2) through fitting of monotonic stress-strain data by the following equation for stress $\sigma$ and plastic strain $\varepsilon^{\mathrm{p}}$ : 


$$
\sigma=k+Q\left[1-\exp \left(-b \varepsilon^{\mathrm{p}}\right)\right]+\sum_{i=1}^{N} \frac{C_{i}}{\gamma_{i}}\left[1-\exp \left(-\gamma_{i} \varepsilon^{\mathrm{p}}\right)\right]
$$

Table 2 Material constants for Chaboche model for AISI type $316 \mathrm{~N}(\mathrm{~L})$ steel at $20^{\circ} \mathrm{C}$ identified using the experimental stress-strain curves and R-O fittings (Gorash et al, 2015, 2014)

\begin{tabular}{cc|cc|cccccccccc}
\hline $\begin{array}{c}k \\
\mathrm{MPa}\end{array}$ & $\begin{array}{c}\mathrm{GPa} \\
\mathrm{N}\end{array}$ & $b$ & $\begin{array}{c}Q \\
\mathrm{MPa}\end{array}$ & $\begin{array}{c}a_{1} \\
\mathrm{MPa}\end{array}$ & $C_{1}$ & $\begin{array}{c}a_{2} \\
\mathrm{MPa}\end{array}$ & $C_{2}$ & $\begin{array}{c}a_{3} \\
\mathrm{MPa}\end{array}$ & $C_{3}$ & $\begin{array}{c}a_{4} \\
\mathrm{MPa}\end{array}$ & $C_{4}$ & $a_{5}$ & $C_{5}$ \\
$\mathrm{MPa}$ & \\
\hline 119.1 & 194 & 558.3 & -119.1 & 454.4 & 60.6 & 134.6 & 899.1 & 54.5 & 14289 & 20 & 267800 & 10.5 & 6729430 \\
\hline
\end{tabular}

\subsection{Results and discussion}

For both the $20^{\circ} \mathrm{C}$ and $538^{\circ} \mathrm{C}$ cyclic opening and closing analysis, it is shown that the spring force $F_{\mathrm{sp}}$ is required to increase to maintain the desired set pressure as shown in Fig. 9. The percentage increase shown in Fig. 9 is calculated by:

$$
\Delta F_{\mathrm{sp}}=\frac{F_{\mathrm{sp}-\mathrm{FE}}}{F_{\mathrm{orf}}} \cdot 100
$$

The $538^{\circ} \mathrm{C}$ simulation shows roughly a 1.5 point higher set force than at $20^{\circ} \mathrm{C}$ at $8.88 \%$. This is maintained for the first 3 cycles which slightly increases at the $4^{\text {th }}$ to $8.93 \%$. There is a sharp increase to $9.45 \%$ after which there is an oscillation between $9.3 \%$ and $9.45 \%$. This oscillation lasts until the 15 th cycle after which a $9.4 \%$ increase in $F_{\mathrm{sp}}$ is maintained for the rest of the 100 cycles.

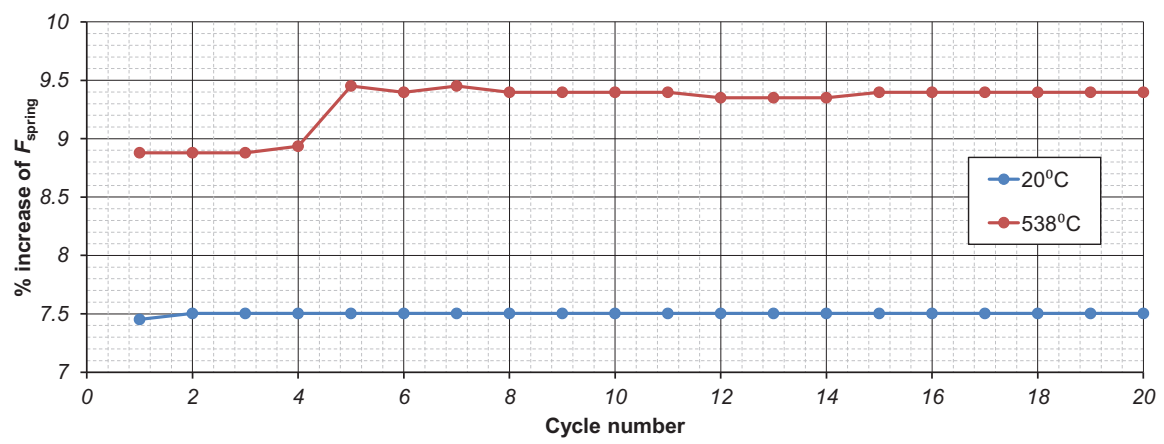

Fig. 9 Spring force (\%) increase to account for plastic strain development across contacting faces 
This transition between $8.88 \%$ and $9.45 \%$ can be explained by analysing the plastic deformation across the contacting seat face (see Fig. 10). The whole of the seat face becomes plastically strained with concentration zones at the internal and external edge (with the former being more significant). Of course the graph is only associated with the seat face. The extent of the plastic zone across the seat is shown in Fig. 11 with the two concentration zones being visible again. As can be seen from Fig. 11, the disc remains elastic and does not undergo any plastic strain. As the cycles increase the plastic strain at the edges increases significantly - internal edge from $0.1 \%$ (1st cycle) to $0.38 \%$ (100th cycle) and at the external edge - from $0.03 \%$ (1st cycle) to $0.25 \%$ (100th cycle). The internal plastic zone is most prevalent from $0-0.5 \mathrm{~mm}$ while the external edge is $1.08 \mathrm{~mm}-1.25 \mathrm{~mm}$. Since this was an idealised model it is clear that the edges no longer remain square and do deform into radial edges, with a small mound shaped middle section (ranging from $0.4 \mathrm{~mm}-1 \mathrm{~mm}$ ).

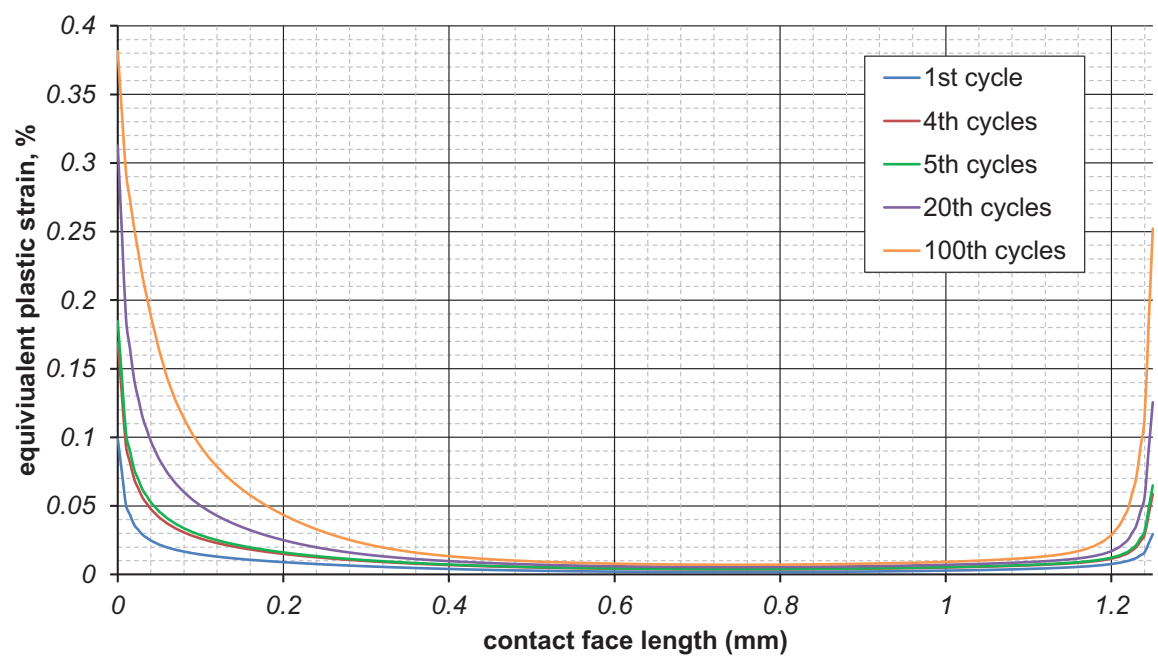

Fig. 10 Equivalent plastic strain (\%) across seat length (mm)

The significant internal plastic zone is due to a combination of the $F_{\mathrm{sp}}$, FPP and internal pressure (based on the macro and micro pressure distribution). As the plastic deformation of the contact face increases, the FPP is allowed to migrate further into the contact zone. This requires an increase in the spring force to maintain the required set pressure.

\subsection{Conclusion}

Using FE-code ANSYS 16.1, it has been shown that to maintain a required set pressure of $18.6 \mathrm{MPa}$ for a gas at a temperature of $538^{\circ} \mathrm{C}$, the spring force must be 


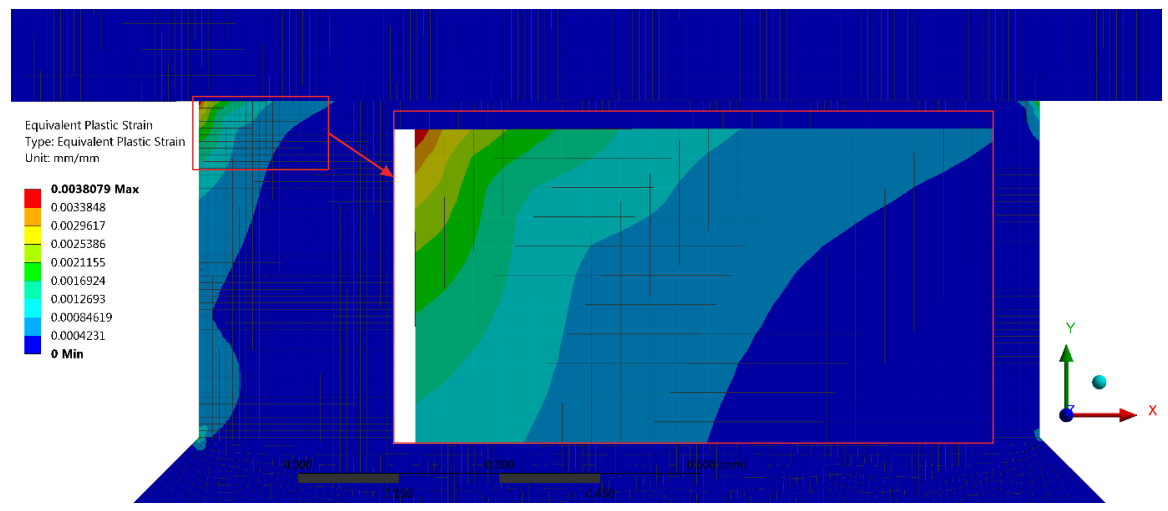

Fig. 11 Equivalent plastic strain of seat and disc at 100 cycles

increased between $8.88 \%$ and $9.45 \%$. This has been found to be adequate for up to 100 cycles of the valve opening and closing. This increase in spring force is found to be due to the lower yield stress and plastic strain conditions of stainless steel $316 \mathrm{~N}(\mathrm{~L})$ at $538^{\circ} \mathrm{C}$, combined with FPP and the micro pressure distribution representing the surface roughness. This idealised model did show a significant amount of plastic strain at the internal edge of the seat extending from 0 to $0.5 \mathrm{~mm}$ in length.

\section{Surface form and waviness at the micro and nanometre scale}

\subsection{Surface metrology measurements and investigations}

The work so far has focused on 2D axisymmetric FEA with an implicit assumption that the surface finish is "flat", i.e. there is no deviation in the surface form. As mentioned in the Introduction (Sec. 1) recommendation 3 - "a multi-scale model accounting for surface roughness deformation" - could be now implemented. However, it was found that the surface form of the discs and seats given by the sponsor varied in magnitude. Therefore, this implicit assumption that the seats are "flat" is no longer valid and recommendation 3 was not the correct course of action.

After some adjustments to the finishing technique used to polish the discs and seats, it was found that the disc surface form dramatically reduced. Importantly the finishing technique used created consistently the same surface finish shape and deviation of about $\pm 0.5 \mu \mathrm{m}$. Using the Alicona Infinite Focus (a confocal and variable focus metrology measurement instrument), it was possible to measure the contacting faces of both the seat and the disc. The surface form measurements of both the valve seat and disc are shown in Fig. 12 and Fig. 13.

As can be seen in Fig. 12, the valve seat has a deviation of $2.1 \mu \mathrm{m}$ in the surface form profile and has almost got a $1 / 4$ symmetric shape to the surface profile. Similarly 


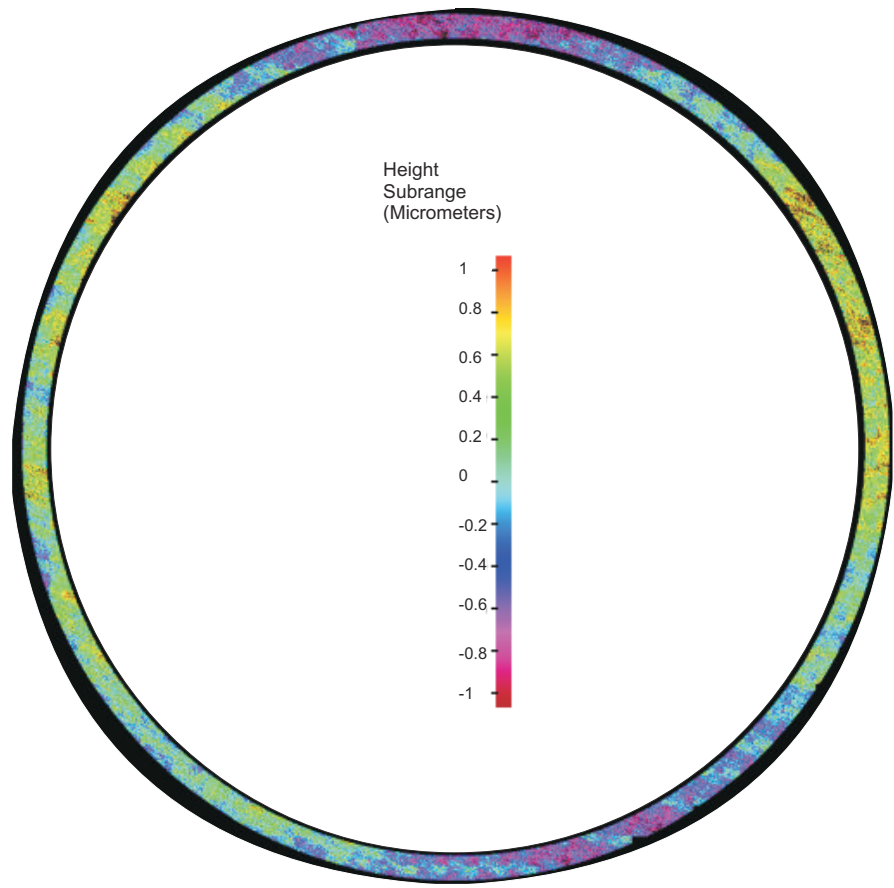

Fig. 12 Surface form of valve seat measured using the Alicona Infinite Focus at 20X objective magnification finding a deviation from the surface form (flatness) of $2.1 \mu \mathrm{m}$

the valve disc has deviation of $5 \mu \mathrm{m}$ and has a clear and distinct $1 / 4$ symmetric shape to the surface profile. This profile is termed as a "saddle" shape (Kemet International Limited, 2015).

As mentioned in the Literature review (Sec. 2), there is no mention of surface form and its relationship to leakage. Instead preference is given to surface roughness. In an industrial environment, flatness is generally measured using a monochromatic light source. There is a known uncertainty called $2 \pi$ ambiguity with monochromatic light sources, which induce errors into the measurement.

Since it is a metallic contacting surface, majority of work with respect to leakage is with metal gaskets, where it is assumed the gasket deforms to the point that surface form is no longer a large enough factor to consider with leakage or flatness is only considered. Preference is generally given to surface roughness and waviness rather the surface form shape.

The reality is that there no such thing as a "perfectly flat" surface, which is a term associated with when using a monochromatic light source to measure flatness. Even with the best of finishing techniques there will be some deviation even in the nanometre range. 


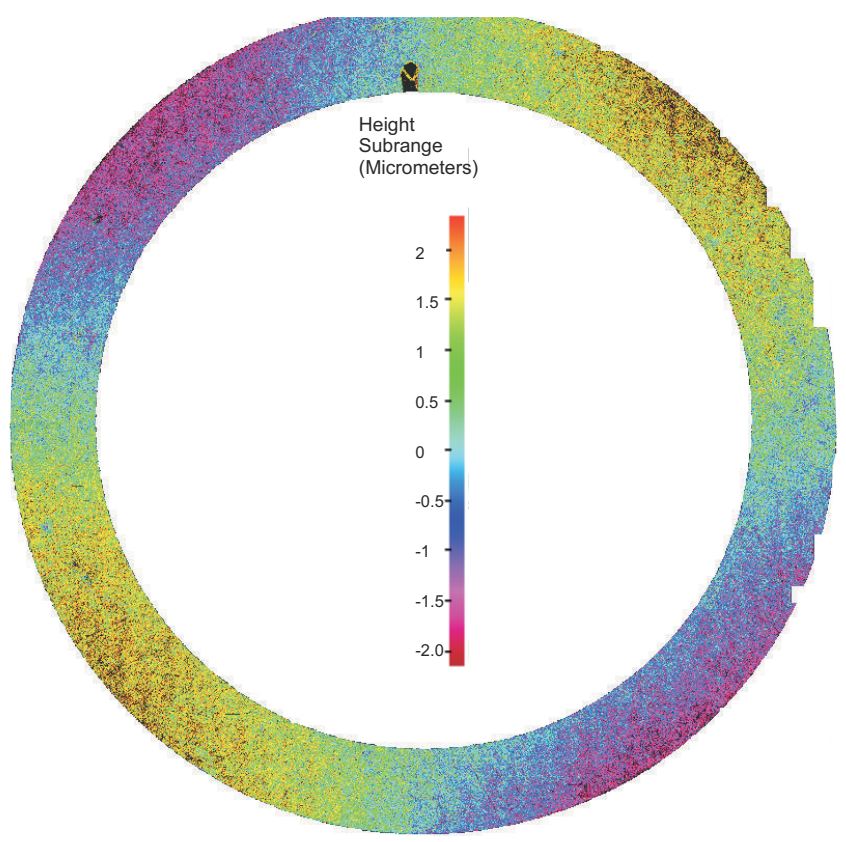

Fig. 13 Surface form of valve seat measured using the Alicona Infinite Focus at 20X objective magnification finding a deviation from the surface form (flatness) of $5 \mu \mathrm{m}$

\subsection{Modelling Surface form and waviness at the macro-nanometre scale}

Taking this surface form shape and waviness into consideration it can be modelled using simplistic surface geometries, in the shape of pyramids, combined with the sum surface technique originally created by Tsukizoe and Hisakado (1965) as shown below in Fig. 14.

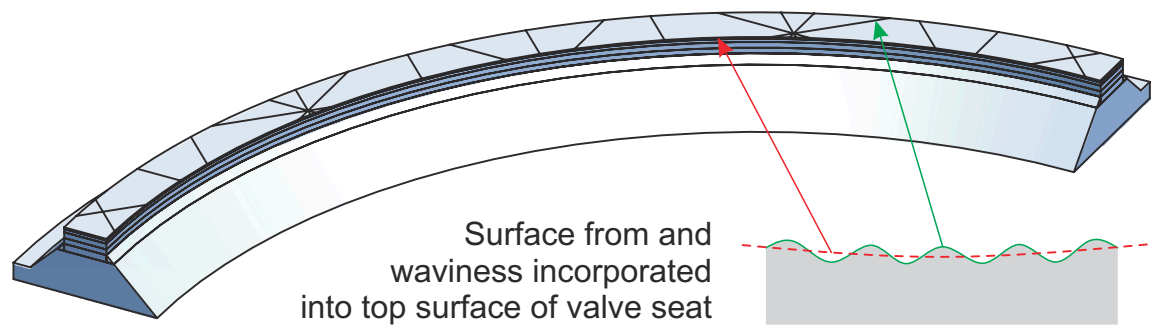

Fig. $141 / 4$ symmetry model of valve seat with surface form $\left(7.1 \mu \mathrm{m}\right.$ deviation) and waviness $\left(W_{\mathrm{a}}\right.$ $=312 \mathrm{~nm}$ and $W_{\mathrm{sm}}=2.35 \mathrm{~mm}$ ) incorporated into top surface 
As seen earlier the surface form is simplified into a $1 / 4$ symmetric 3D Computer Aided Design (CAD) model. Using the summing technique, the surface form is modelled as a deviation of $7.1 \mu \mathrm{m}$ and waviness: $W_{\mathrm{a}}=312 \mathrm{~nm}$ and $W_{\mathrm{sm}}=2.35 \mathrm{~mm}$. The model is first created over a $2 \mathrm{D}$ rectangle, after which the valve seat face is cut out. From this the rest of the valve seat can be modelled.

Using a theoretical approach to modelling of waviness and surface form, radial sinusoidal waves describing waviness can be schematically presented by the following equation:

$$
W_{\mathrm{r}}=\cos \left[\left(x^{2}+y^{2}\right)^{1 / 2}\right],
$$

which is shown as contour plot in Fig. 15a and as 3D plot in Fig. 16a. As discussed, the $W_{\mathrm{a}}$ and $W_{\mathrm{sm}}$ are respectively found to be in the nanometer and millimeter range. Therefore, the appropriate unit choice for this study for $x$ and $y$ (and for radial $W_{r}$ and hoop $W_{h}$ waves), will be micrometers. Circumferential (hoop) sinusoidal waves describing surface form can be schematically described by the following equation:

$$
W_{\mathrm{h}}=x \cdot y^{3}-y \cdot x^{3},
$$

which is shown as contour plot in Fig. 15b and as 3D plot in Fig. 16b. A combination of radial and hoop waves, which is usually expected in real contacting surfaces, can be schematically presented by the product of Equations (20) and (21) as $W_{\mathrm{c}}=W_{\mathrm{r}} \cdot W_{\mathrm{h}}$ and shown as contour plot in Fig. 15c and as 3D plot in Fig. 16c.
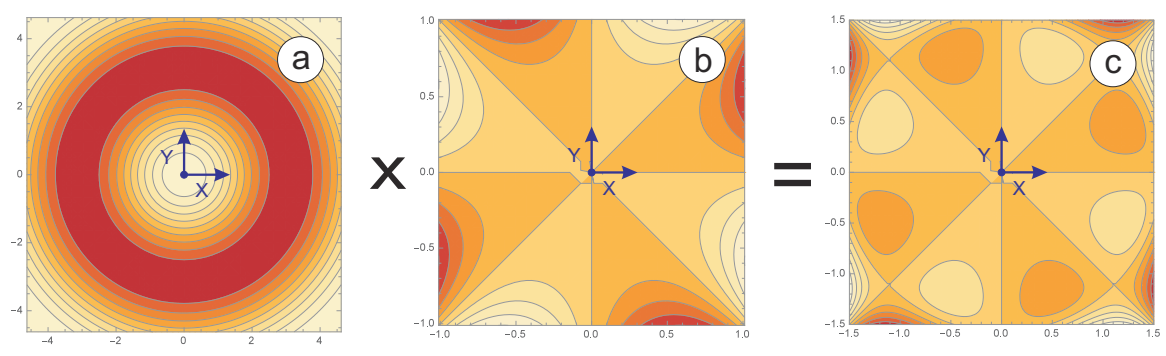

Fig. 15 Schematic contour plots of the sealing surface waves: (a) radial, (b) circumferential (hoop) and (c) their combination

Sinusoidal waves would be better to model the geometry with, however, it has been found that the CAD software, SolidWorks 2013 is not capable of creating sinusoidal waves due to the $W_{\text {sm }}$ length versus the $W_{\mathrm{a}}$. The $W_{\text {sm }}$ versus $W_{\mathrm{a}}$ ratio creates a difficulty within the CAD engine to model due to the line being so close to being linear. It was found that a ratio of about $W_{\mathrm{sm}} / W_{\mathrm{a}}<2500$ can be modelled in SolidWorks 2013 as a sinusoidal wave. This model will be structurally deformed using non-linear FEA considering plasticity in ANSYS and will be reported on later in the year in a GAMM 2016 conference (Anwar et al, 2016a) and in length as part of the thesis. 

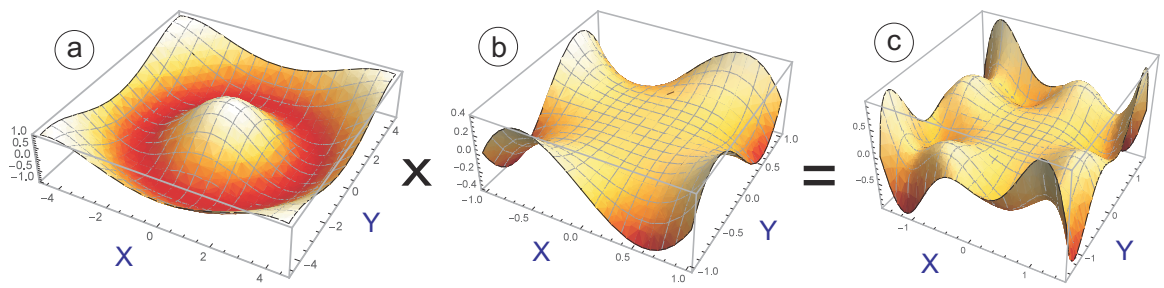

Fig. 16 Schematic 3D plots of the sealing surface waves: (a) radial, (b) circumferential (hoop) and (c) their combination

\section{Overall conclusion}

The overall conclusions drawn so far are:

- The literature with respect to PRV leak tightness is few and far between. However, inspiration is drawn from metal-to-metal contacting surface such as gaskets. There is a lot information and research conducted to account for surface roughness and some on waviness and its effect on leakage.

- The elevated temperature effects on the 2D axisymmetric FEA showed that the FPP was capable of migrating further along the contacting faces due to the cyclic softening of the material. This meant that the spring force would have to be readjusted after the first 5 cycles.

- After measuring the surface faces of the seat and the disc, it was found that the surface form was at a micrometre magnitude with a $1 / 4$ symmetry shape and the waviness is exhibited over a nanometre range.

\section{Future direction}

With respect to the research conducted so far, the biggest change is taking into account of the surface form and waviness. Therefore, the overall the direction is shown in Fig. 17.

In regards to the 1-way coupling between FEA and CFD this will be reported on in the GAMM 2016 conference (Anwar et al, 2016a). This will focus on the techniques used. The initial CFD validation work has been completed and will be reported on at the ASME PVP 2016 conference (Anwar et al, 2016b). The measurements taken using the Alicona Infinite Focus have shown the average roughness $\left(R_{\mathrm{a}}\right)$ is about a 10th of the waviness. The surface roughness will be modelled over a small representative surface using real scanned surfaces and then deformed using FEA. This will be reported on in the near future. 


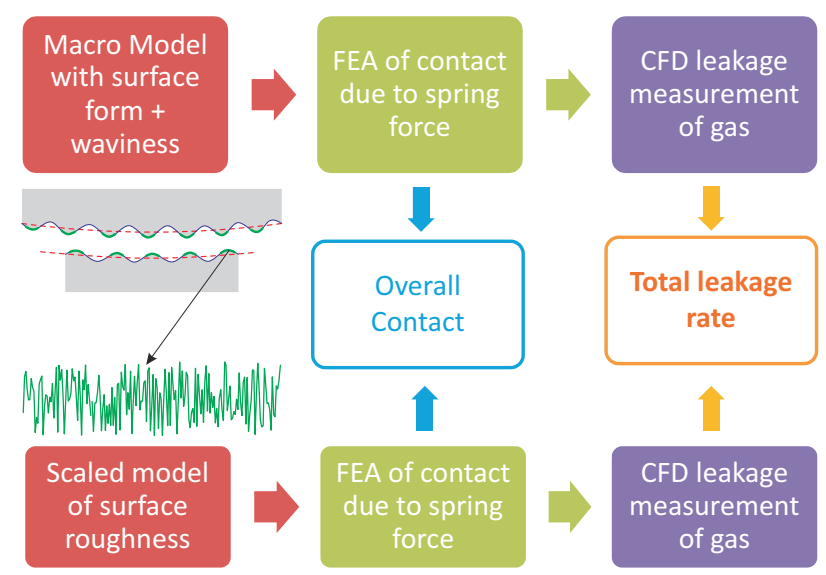

Fig. 17 Overall research direction for PRV leak tightness investigation and model development

\section{Acknowledgements}

There are many people without whom this research project could have not have been possible. The authors would like to thank:

- The individuals who's research has been mentioned in this paper, since without their great work, this literature review would have not come about;

- Colleagues and supervisors, in particular, Robert Hamilton and David Nash;

- The WEIR group and the WEIR Advanced Research Center (WARC) in particular, Allan Bickley, Allan Stewart, Ian MacQueen, Stéphane Carrier and Fabrice Courdavault;

- Brian Kyte (Sales Director at Alicona UK) for the help in getting access to the Alicona Infinite Focus and addressing technical matters;

- Liza Hall (University of Strathclyde, Advanced Forming and Research Centre, Metrology) for allowing to use the Alicona Infinite Focus and addressing technical matters;

- Rong Su and Wahyudin Syam (University of Nottingham, Institute for Advanced Manufacturing) for allowing to use the Alicona Infinite Focus and addressing technical matters.

\section{References}

ANSYS $^{\circledR}$ Help (2013) Mechanical APDL // Element Reference // 7. Element Library // Part I: Element Library. ANSYS, Inc., Canonsburg (PA), USA, Academic Research 14.5.7 edn

Anwar AA, Gorash Y, Dempster W, Nash D (2016a) Deformed gap space using macro-micro FEA model and transferred into a CFD model. In: Proc. Joint DMV \& GAMM Annual Meeting (GAMM 2016), GAMM e.V., Braunschweig, Germany, March 7-11, submitted 
Anwar AA, Ritos K, Gorash Y, Nash D, Dempster W (2016b) Leakage of gas flow through a microchannel in the slip flow regime. In: Proc. ASME Pressure Vessels \& Piping Conf. (PVP 2016), ASME, Vancouver, Canada, July 17-21, submitted

API (2014) Seat Tightness of Pressure Relief Valves. No. 527 in API Standard, American Petroleum Institute, Washington, USA

Arkilic EB, Schmidt M, Breuer KS, et al (1997) Gaseous slip flow in long microchannels. J of Microelectromechanical Systems 6(2):167-178, DOI 10.1109/84.585795

ASME (2014) Pressure Relief Devices - Performance Test Codes. No. ASME PTC 25-2014 in An American National Standard, The American Society of Mechanical Engineers, New York, USA

BHR Group Ltd (2000) Valve stem leak - tightness test methodologies. Summary report no. CR1234, European Commission, British Hydromechanics Research Group Ltd., Cranfield, UK

BSI (2013) Safety devices for protection against excessive pressure. Safety valves. No. BS EN ISO 4126-1:2013 in British Standard, The British Standards Institution, London, UK

Burmeister LC, Loser JB, Sneegas EC (1967) Advanced valve technology - Revised and enlarged edition. Technology Survey no. NASA SP-5019, Midwest Research Institute, NASA, Washington, D.C., USA

Chaboche J-L (2008) A review of some plasticity and viscoplasticity constitutive theories. Int J Plasticity 24(10):1642-1693, DOI 10.1016/j.ijplas.2008.03.009

Chong X (2006) Subsonic choked flow in the microchannel. Physics of Fluids 18(12):127,104-1127,104-5, DOI 10.1063/1.2408510

Gagnepain J, Roques-Carmes C (1986) Fractal approach to two-dimensional and three-dimensional surface roughness. Wear 109(1):119-126, DOI 10.1016/0043-1648(86)90257-7

Ganti S, Bhushan B (1995) Generalized fractal analysis and its applications to engineering surfaces. Wear 180(1):17-34, DOI 10.1016/0043-1648(94)06545-4

Geoffroy S, Prat M (2004) On the leak through a spiral-groove metallic static ring gasket. J of Fluids Engineering 126(1):48-54, DOI 10.1115/1.1637627

Gorash Y, MacKenzie D (2014) Safe structural design for fatigue and creep using cyclic yield strength. In: Proc. 3rd Int. ECCC Conf. - Creep \& Fracture in High Temperature Components (ECCC 2014), paper no. ECCC2014-87, Centro Sviluppo Materiali, Rome, Italy, May 5-7

Gorash Y, Altenbach H, Lvov G (2012) Modelling of high-temperature inelastic behaviour of the austenitic steel AISI type 316 using a continuum damage mechanics approach. J of Strain Analysis 47(4):229-243, DOI 10.1177/0309324712440764

Gorash Y, Dempster W, Nicholls WD, Hamilton R (2014) Leak tightness in safety valves: Structural and fluid dynamics analyses, microscopic studies and experimental setup. Report: Project N1a, Weir Advanced Eesearch Centre, University of Strathclyde, Glasgow, UK

Gorash Y, Dempster W, Nicholls WD, Hamilton R (2015) Modelling of metal-to-metal seals in a pressure relief valve using advanced FE-analysis. In: de Hosson JTM, Hadfield M, Brebbia CA (eds) WIT Transactions on Engineering Sciences, vol. 91, WIT Press, Southampton, UK, pp 247-258, DOI 10.2495/SECM150221

Haruyama S, Nurhadiyanto D, Choiron MA, Kaminishi K (2013) Influence of surface roughness on leakage of new metal gasket. Int J of Pressure Vessels \& Piping 111:146-154, DOI 10.1016/ j.ijpvp.2013.06.004

Hyde CJ, Sun W, Leen SB (2010) Cyclic thermo-mechanical material modelling and testing of 316 stainless steel. Int J of Pressure Vessels \& Piping 87(6):365-372, DOI 10.1016/j.ijpvp.2010.03. 007

Jackson RL, Streator JL (2006) A multi-scale model for contact between rough surfaces. Wear 261(11):1337-1347, DOI 10.1016/j.wear.2006.03.015

Kemet International Limited (2015) How to measure flatness - Technical article. URL www.kemet.co.uk/blog/lapping/how-to-measure-flatness-technical-article/, accessed on 11-01-2016.

Ledoux Y, Lasseux D, Favreliere H, Samper S, Grandjean J (2011) On the dependence of static flat seal efficiency to surface defects. Int J Pres Ves \& Piping 88(11-12):518-529, DOI 10.1016/j. ijpvp.2011.06.002 
Man J, Zhou Q, Tao Z, Zhang Y, An Q (2014) Micro-scale numerical simulation on metal contact seal. Proc of IMechE, Part C: J of Mechanical Engineering Science 228(12):2168-2177, DOI 10.1177/0954406213515644

Marie C, Lasseux D (2007) Experimental leak-rate measurement through a static metal seal. J Fluids Eng 129(6):799-805, DOI 10.1115/1.2734250

Megalingam A, Mayuram M (2012) Elastic-plastic contact analysis of single layer solid rough surface model using fem. Int $\mathrm{J}$ of Mechanical, Aerospace, Industrial, Mechatronic and Manufacturing Engineering 6(1):133-137

Mitchell L, Rowe M (1969) Influence of asperity deformation mode on gas leakage between contacting surfaces. J of Mechanical Engineering Science 11(5):534-549, DOI 10.1243/JMES_ JOUR_1969_011_065_02

Müller HK, Nau BS (1998) Fluid Sealing Technology: Principles and Applications. Marcel Dekker, Inc., New York, USA

O'Callaghan P, Probert S (1987) Prediction and measurement of true areas of contact between solids. Wear 120(1):29-49, DOI 10.1016/0043-1648(87)90131-1

Pérez-Ràfols F, Larsson R, Almqvist A (2016) Modelling of leakage on metal-to-metal seals. Tribology International 94:421-427, DOI 10.1016/j.triboint.2015.10.003

Ritchie G (1989) Minimizing pressure relief valve seat leakage through optimization of design parameters. BSc thesis, Dept. of Mechanical Engineering, MIT, Massachusetts, USA

Robbe-Valloire F, Prat M (2008) A model for face-turned surface microgeometry: Application to the analysis of metallic static seals. Wear 264(11):980-989, DOI 10.1016/j.wear.2007.08.001

Robbe-Valloire F, Paffoni B, Progri R (2001) Load transmission by elastic, elasto-plastic or fully plastic deformation of rough interface asperities. Mechanics of Materials 33(11):617-633, DOI 10.1016/S0167-6636(01)00074-6

Singh A, Bernstein MD (eds) (1983) Testing and Analysis of Safety / Relief Valve Performance, United Engineering Center, ASME, New York, USA, Proc. of ASME conferences

Smith E, Vivian BE (1995) An Introductory Guide to Valve Selection. Introductory Guide Series (REP), Wiley

Spirax Sarco (2016) Steam engineering tutorials: Introduction to safety valves. URL www.spiraxsarco.com/Resources/Pages/Steam-Engineering-Tutorials/safety-valves/ introduction-to-safety-valves.aspx, accessed on 05-01-2016.

Thompson MK (2007a) Geometric primitive surface roughness in finite element models. 2007 Annual Meeting for the Society of Tribologists and Lubrication Engineers, Philadelphia, PA

Thompson MK (2007b) A multi-scale iterative approach for finite element modeling of thermal contact resistance. PhD thesis,, Dept. of Mechanical Engineering,, Massachusetts Institute of Technology, Cambridge, USA

Thompson MK (2011) A comparison of methods to evaluate the behavior of finite element models with rough surfaces. Scanning 33(5):353-369, DOI 10.1002/sca.20252

Thompson MK, Thompson JM (2010a) Considerations for the incorporation of measured surfaces in finite element models. Scanning 32(4):183-198, DOI 10.1002/sca.20180

Thompson MK, Thompson JM (2010b) Methods for generating probabilistic rough surfaces in ANSYS. In: Proc. 20th Korea ANSYS User's Conf., ANSYS Inc., Gyeongju (Sep. 9-10), South Korea

Tsukizoe T, Hisakado T (1965) On the mechanism of contact between metal surfaces - The penetrating depth and the average clearance. J of Basic Engineering 87(3):666-672, DOI $10.1115 / 1.3650635$

University of Cambridge (2004) Teaching packages: Slip line field theory. URL www.doitpoms.ac.uk/tlplib/metal-forming-3/slip_line_field.php, accessed on 13-10-2014.

Uppal A, Probert S (1972) Deformation of single and multiple asperities on metal surfaces. Wear 20(3):381-400, DOI 10.1016/0043-1648(72)90417-6

Vallet C, Lasseux D, Sainsot P, Zahouani H (2009) Real versus synthesized fractal surfaces: Contact mechanics and transport properties. Tribology Int 42(2):250-259, DOI 10.1016/j.triboint. 2008. 06.005

Zappe RW (2004) Valve Selection Handbook. Gulf Professional Publishing, Oxford, UK 